\title{
Environmental Ethics of Water Resources Management
}

\author{
Amad Deen Abdusalam Alghwail \\ Elmergib University, Alkhums, Libya
}

\begin{abstract}
Scarcity and sustainability of water resources are the most important problem amongst the major problems that human faces in the present and will increasingly face in the future. The current water crisis is complex and a result of several factors. Sustainable management of water resources is imperative as water scarcity is becoming a development constraint, impeding the economic growth of many countries in the globe. Environmental ethics can be a valuable tool for sustainable resource management in any region in the globe. Recognizing water as finite and vulnerable involves a holistic approach, linking social and economic with ecosystem protection, and should be applied across a whole catchments area or groundwater aquifer. This holistic approach is an important implication of the finite nature of water.
\end{abstract}

Keywords: water scarcity, freshwater, environmental ethics, water resources management, sustainability of water

\section{Introduction}

Water is one of the most widely distributed substances across the world's surface and is crucial for a variety of aspects of human health, development, and well-being as well as for the functioning of natural ecosystems. The importance of water has continued to be recognized with the incorporation thereof into the new Sustainable Development Goals (SDGs) which are Global Goals primarily set to transform the world and part of the 2030 Agenda for sustainable development. Water has thus been continually recognized as a fundamental human right internationally and it is vital that it be managed effectively and efficiently on a global and national scale.

The main water use sectors, grouped in terms of agriculture, industrial (includes industrial activities, mining, and energy) as well as municipal/domestic, recreational, and environmental water use, have an influence on water availability through physical water abstraction as well as through water degradation. Global challenges in terms of water availability and water use are highlighted. Focus is placed on the availability, distribution, and use of freshwater resources on a global scale.

\section{Distribution of Water in the Earth}

About of three quarters of the earth's surface is covered by water. The distribution of water on the earth, based on human economic needs for freshwater, is represented in Figure 1 (Lui et al., 2011).

The earth's hydrosphere contains about 1,386 million $\mathrm{km}^{3}$ of water. However, not all of these resources are potentially available to humans since freshwater is required by the agricultural sector, industries, and

Amad Deen Abdusalam Alghwail, Ph.D. in Civil Engineering (Hydraulics \& Water Resources Engineering, Environmental Engineering), lecturer at Faculty of Engineering, Head of Civil Engineering Department, Elmergib University, Alkhums, Libya.

Correspondence concerning this article should be addressed to Amad Deen Abdusalam Alghwail, Libya, Faculty of Engineering, Alkhums, Arriadyah Street, Libya. 
domestic and recreational users (Lui et al., 2011; Kibona, Kidulile, \& Rwabukambara, 2009; Cassardo \& Jones, 2011). Figure 1 shows that approximately $3 \%$ of the water on the earth is freshwater in different physical states liquid, gas, or solid, while $30 \%$ of freshwater comes from groundwater. Only $0.3 \%$ of the freshwater on the earth is contained in river systems, lakes, and reservoirs.

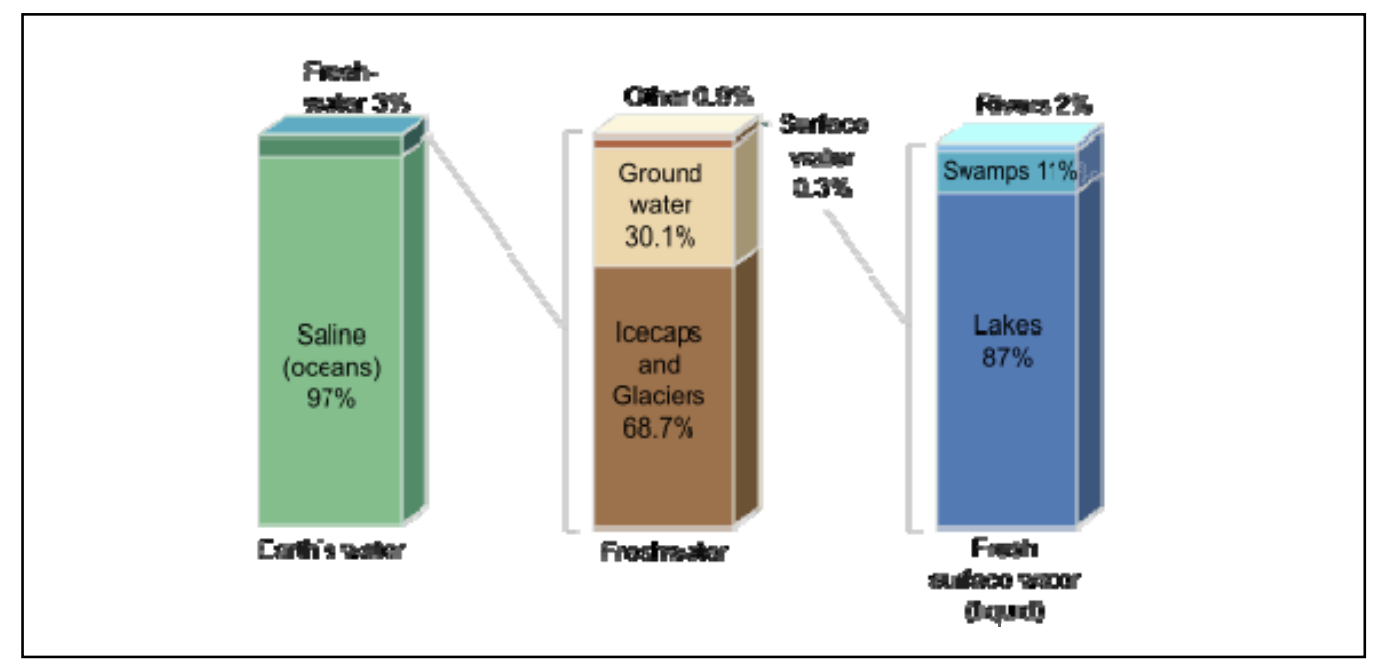

Figure 1. Earth’s water distribution.

As clarified in Figure 2, approximately 99\% of water is described as unfit or unavailable for human consumption. The remaining $1 \%$ consists mainly of groundwater, which can be difficult and costly to obtain. Only $0.0067 \%$ of the total water on the earth is fresh surface water that can be used. This leaves a total of around 2,120 $\mathrm{km}^{3}$ of freshwater that is available for human use and consumption (Cassardo \& Jones, 2011).

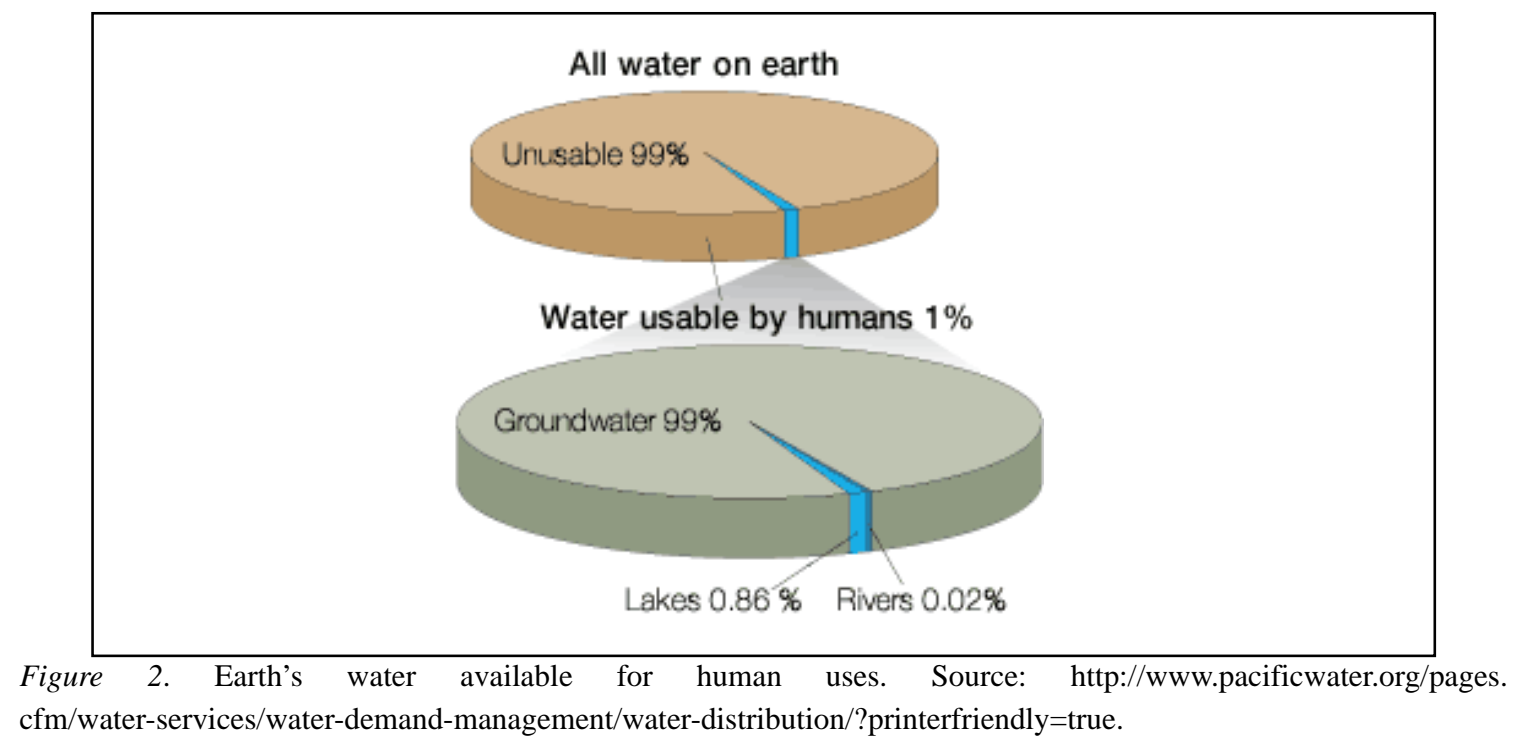

According to Pimentel et al. (2010), the most fundamental function of water is firstly as a prerequisite for life on the earth and secondly, as a commodity or economic resource. These two roles are constantly in conflict with each other in many areas of water usage. This has led to the exploitation of water through human activities which has in turn placed huge risks on aquatic ecosystems and the life that they support. 


\section{Water Uses and Consumption}

Water is used for many different purposes throughout our economies and natural ecosystems. In urban or residential settings, water is used for a wide range of daily activities, which include cooking, washing and bathing, small-scale irrigation for gardens, waste disposal, and commercial and industrial activities.

\section{Water in Agriculture}

It has recently been estimated that nearly $69 \%$ of worldwide usage of water is for agriculture, mainly in the form of irrigation (Kibona et al., 2009; Cassardo \& Jones, 2011; Rosegrant, Ringler, \& Zhu, 2009). Agriculture is by far the largest user of water worldwide. Most observers put total consumptive use of water worldwide for irrigated agriculture at nearly $85 \%$ of total human consumptive use (Food and Agriculture Organization of the United Nations, 2002).

\section{Industrial Water Use}

Industrial water usage is the second-largest consumer of water in the world. In some industrialized nations, a substantial portion of total water withdrawals is used for the production of energy (hydroelectric plants or cooling). In the US, $47 \%$ of total water withdrawals went to power plant cooling (Solley, Pierce, \& Perlman, 1998; European Environment Agency, 1999). Another example, abstractions for the manufacturing industry (including for cooling purposes electricity production) account for more than $50 \%$ of total gross abstractions in most European countries, as shown in Figure 3.

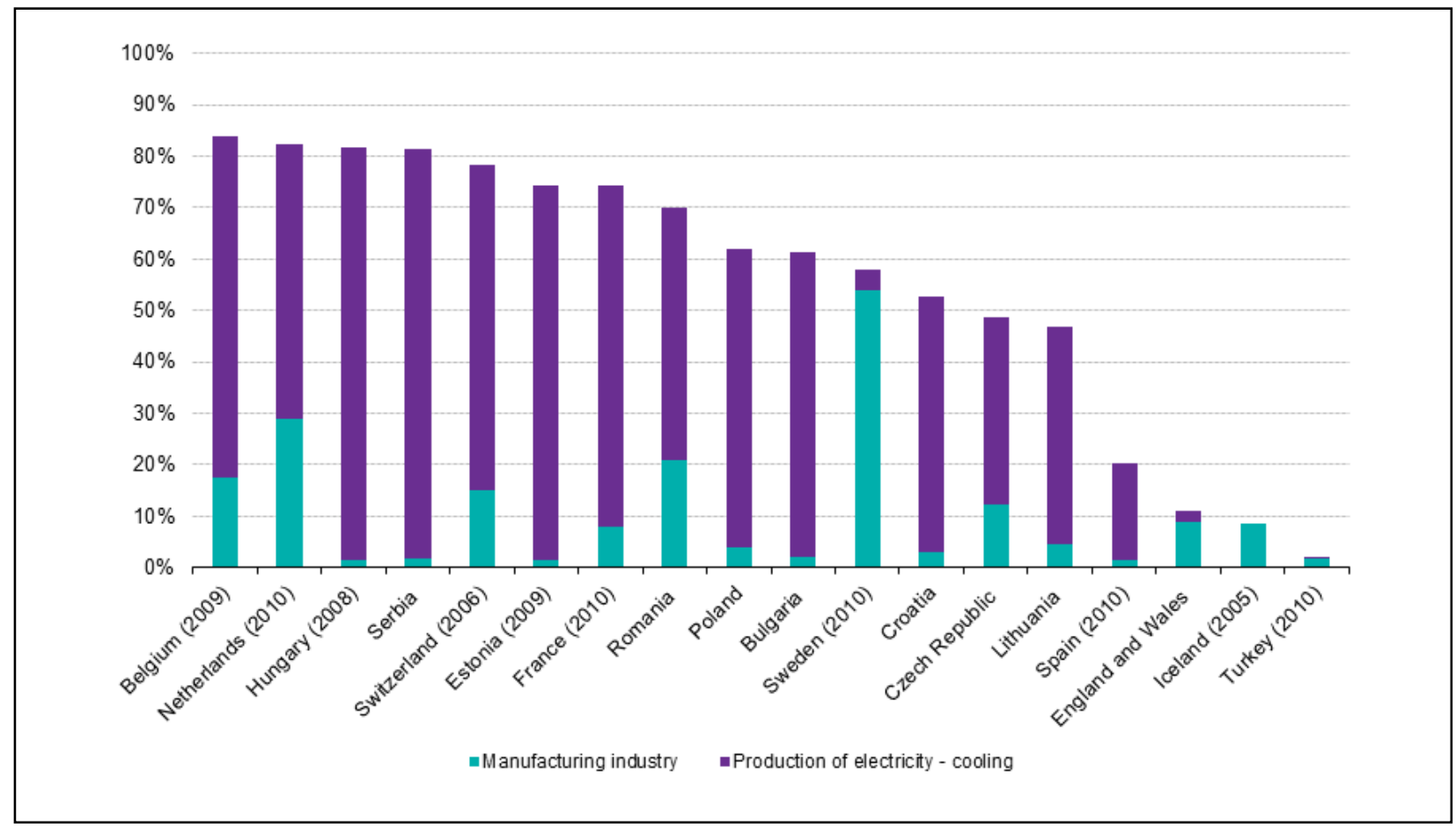

Figure 3. Proportion of abstractions for the manufacturing and production of electricity cooling industries in Europe. Source: http://ec.europa.eu/eurostat/product?code=env_wat_abs\&language=en\&mode=view.

\section{Domestic, Recreational, and Environmental Water Use}

The worldwide water use for household purposes is around $15 \%$ and constitutes the third-largest water consumer globally. Basic household water requirements have been estimated by Gleick (2006) at around 50 l/c/d. 
Recreational water use accounts for only $1 \%$ of the world's consumption but this percentage is increasing slowly. This type of water use is associated with reservoirs. The water is categorized as recreational if the reservoir is kept fuller for storage purposes than it would otherwise be.

Finally, environmental water usage uses the least water of all the categories mentioned previously and benefits ecosystems rather than human beings. The total water usage is increasing as a result of artificial wetlands, artificial lakes intended to create wildlife habitat, fish ladders around dams, and water releases from reservoirs timed to help fish spawn (Lui et al., 2011; Kibona et al., 2009; UN, 2012).

\section{Groundwater Use}

Groundwater development has for a long time provided drinking water to urban and rural populations of developed and developing countries. As reported by United Nations (2003), currently groundwater is estimated to provide about $50 \%$ of the world's drinking-water supplies. Moreover, groundwater is arguably the cheapest and fastest way to achieve the United Nations Millennium Declaration goal of halving the number of people worldwide without affordable drinking water and/or malnourished by 2015 (Llamas \& Martinez, 2002). In addition, groundwater abstraction by simplified mechanisms, such as the treadle pump, together with cheap drip irrigation systems, also constitutes a plausible alternative for developing countries to overcome the poverty threshold (one dollar/person and day per capita income) (Polak, 2004).

\section{Ethical Issues of Water Management}

Different societies have different moral characters, but it seems to be worldwide the importance of water, generally valued and respected in all cultures. As mentioned above, only 3\% is fresh water. More than 5 million people continue dying annually from water related problems, 1.4 billion people live with no access to drinking water (25\% of the world population), 2.9 billion (around $50 \%$ of the world population) do not have basic sanitary service, and 6,000 children die every day due to this problem.

From principle of human dignity and equality, all people have the right to have access to drinking water in quantities and of a quality equal to their basic needs, as clamed in the UN Universal declaration of Human Rights of 1948 and the proclamation of the 1977 UN Water Conference.

From the perspective of the principle of precaution in the sense of sustainable development, Should developed countries reduce their water consumption so that developing countries can develop? Should we rely on technology to save us in the future, such as, desalination of sea water? Should we be more active in conservation? Indeed, it is very hard to have a global approach on any issue that concerns different realities, cultures, political structures, and economic situation with these principles because the earth is one but the world is not.

Table 1 illustrates key facts about drinking water as reported in World Health Organization (WHO) in 2015.

\section{Table 1}

Key Facts About Drinking Water as Reported in (WHO) in 2015

\begin{tabular}{l} 
Key facts about drinking water \\
Seventy-one percent of the global population (5.2 billion people) used a safely managed drinking water service that is, one \\
located on premises, available when needed, and free from contamination. \\
\hline $\begin{array}{l}\text { Eighty-nine percent of the global population (6.5 billion people) used at least a basic service. A basic service is an improved } \\
\text { drinking-water source within a round trip of } 30 \text { minutes to collect water. }\end{array}$ \\
\hline
\end{tabular}


(Table 1 to be continued)

Eight hundred and forty-four million people lack even a basic drinking-water service, including 159 million people who are dependent on surface water.

Contaminated water can transmit diseases such diarrhea, cholera, dysentery, typhoid, and polio. Contaminated drinking water is estimated to cause 502,000 diarrheal deaths each year.

By 2025, half of the world's population will be living in water-stressed areas.

In low and middle income countries, 38\% of health care facilities lack an improved water source, 19\% do not have improved sanitation, and 35\% lack water and soap for handwashing.

\section{Water Sustainability}

Sustainability is defined as human development that meets the needs of present generation without compromising the ability of future generations to meet their own needs.

In debating the use of water and sustainability, we should consider that protecting the water environment is an ethical imperative and we must pursue to identify the value of nature beyond anthropocentric utilitarianism. Only then will it be possible to resolve conflicts that arise in water management between present and future generations, between human and non-human users, and between human competing users. We must engage a "water ethic" that will serve as a touchstone for the evaluation of the environmental action and policy. Society must first ensure that appropriate prioritization of water access is put in place which allows humanity's essential needs to be met as well as those of our ecosystems (Selborne, 2001). Accepting the problem is the first step towards an international pact that will act on sustainability and a social equality. In this way, we will be able to manage the water supply in a sustainable way and adjust this ethical challenge to its political and economic dimension, as an instrument of development and cooperation between nations.

Overall, water as a resource to be managed carefully, sustainably, and equitably has only emerged as an international topic in the last two decades; water has moved from becoming a significant topic to becoming a topic worthy of its own genre of ethics.

\section{Conclusion}

The goals of water ethics are equity and sustainability. They are intended not as a final status but as a continuous process to be carried out in the management of this resource in the future. In this direction, many organizations have discussed (Working Group on the Use of Fresh Water Resources [UNESCO], 1998; World Commission on the Ethics of scientific knowledge and Technology [COMEST, Oslo], 1999; United Nations Conference on Environment and Development; Dublin Statement on Water and Sustainable Development [ICWE], 1992).

Water is limited in its amount on the earth. While this fact is not ethical, its implications are ethical as this understanding is absolutely fundamental to how we manage our use of water and is thus a principle deserving of specific discussion. Factors of population growth, lifestyle affluence, habitat destruction, land use, pollution, and the implications of climate change mean water can no longer be treated as an inexhaustible resource. Due to these factors, together with spatial and temporal variations in water availability, water is becoming relatively scarcer. The limited but renewable nature of water, its geographic distribution, and its variability in annual and seasonal availability condition water use and human activity.

\section{References}

Cassardo, C., \& Jones, J. A. A. (2011). Managing water in a changing world. Water, 3, 618-628. 
European Environment Agency. (1999). Sustainable water use in Europe. Copenhagen, Den.: EEA.

Food and Agriculture Organization of the United Nations. (2002). FAO Aquastat database. Retrieved from http://www.fao.org

Gleick, P. (2006). The world's water: The biennial report on freshwater resources. Washington: Island Press.

Kibona, D., Kidulile, G., \& Rwabukambara, F. (2009). Environment, climate warming and water management. Transition Studies Review, 16, 484-500.

Llamas, M. R., \& Martinez, C. L. (2002). Groundwater irrigation and poverty alleviation. IWRA Regional Symposium: Water for Human Survival, 27-30 November, New Delhi, India.

Lui J., Dorjderem, A., Lei, X., Liu, H., Macer, D., Qiao, Q., Sun, A., ... Zheng, Y. (2011). Water ethics and water resource management. Ethics and Climate Change in Asia and the Pacific (ECCAP) Project Working Group 14 Report, UNESCO, Bangkok.

Pimentel, D., Whitecraft, M., Scott, Z. R., Zhao, L. X., Satkiewicz, P., Scott, T. J., Phillips, J., ... Moe, T. L. (2010). Will limited land, water, and energy control human population numbers in the future. Human Ecology, 38(5), 599-611.

Polak, P. (2004). Water and the other three revolutions needed to end rural poverty. Invited paper in the World Water Week, 15-20 August, Stockholm International Water Institute, Stockholm.

Rosegrant, M. W., Ringler, C., \& Zhu, T. (2009). Water for agriculture: Maintaining food security under growing scarcity. Annual Review of Environmental Resources, 34, 205-222.

Selborne, L. (2001). A Ética do Uso da Água Doce: Um levantamento. Brasília: UNESCO.

Solley, W. B., Pierce, R. R., \& Perlman, H. A. (1998). Estimated use of water in the United States in 1995. U.S. Geological Survey Circular 1200. Retrieved from https://pubs.usgs.gov/circ/1998/1200/report.pdf

United Nations (UN). (2003). Water for people, water for life. Paris: UNESCOWWAP.

UN. (2012). The United Nations world water development report. Retrieved from https://www.unwater.org/publications/managing-water-uncertainty-risk/ 